\title{
RETRACTED ARTICLE: Industrial bio-based plant aggregates as hygric and insulating construction materials for energy efficient building
}

\author{
Yunhong Jiang $(\bowtie)^{1,2}$, Mike Lawrence ${ }^{1}$, Meng Zhang ${ }^{2}$, Jiandong Cui ${ }^{3}$
}

1 BRE Centre for Innovative Construction Materials, Department of Architecture and Civil Engineering, University of Bath, Bath, BA2 7AY, UK

2 Hub for Biotechnology in the Built Environment, Department of Applied Sciences, Faculty of Health and Life Sciences, Northumbria University, Newcastle-upon-Tyne, NE1 8ST, UK

3 Key Laboratory of Industrial Fermentation Microbiology, Tianjin University of Science and Technology, Tianjin Economic and Technological Development Area (TEDA), Tianjin 300457, China

(C) The Author(s) 2020. This article is published with open access at link.springer.com and journal.hep.com.cn

The authors have retracted this article because it overlaps with a previously published article [1]. All authors agree to this retraction. The online version of this article contains the full text of the retracted article as electronic supplementary material.

\section{References}

1. Marie Viel, Florence Collet, Christophe Lanos, Chemical and multi-physical characterization of agro-resources' by-product as a possible raw building material, Industrial Crops and Products, Volume 120, 2018, Pages 214-237

Received March 3, 2020

E-mails: yunhong.jiang@northumbria.ac.uk, yunhongjiang@yahoo.com 